\title{
A gestão democrática no Nordeste \\ As formas de provimento do cargo de gestor escolar
}

\author{
The democratic management in the Northeast
}

The forms of filling the position of school manager

\section{La gestión democrática en el Nordeste \\ Las formas de provisión del cargo de gestor escolar}

\author{
ISABELA MACENA DOSSANTOS* \\ Universidade Federal de Alagoas, Maceió- AL, Brasil \\ EDNA CRISTINA DO PRADO** \\ Universidade Federal de Alagoas, Maceió- AL, Brasil
}

\begin{abstract}
RESUMO: O Nordeste Brasileiro adotou, como a maioria das regiões, a gestão democrática, prevista na Lei de Diretrizes e Bases da Educação Nacional (LDBEN) n 9394/96 como princípio orientador da forma de provimento ao cargo de gestor escolar. Este artigo visa trazer à tona como se processou ou está se processando a escolha do gestor escolar dos municípios de cinco estados do Nordeste Brasileiro: Alagoas, Ceará, Paraíba, Pernambuco e Rio Grande do Norte. Com recursos advindos do Edital Universal- CNPq foi possível realizar o estudo, utilizando uma metodologia quanti-qualitativa.

Palavras-Chave: Gestão democrática. Provimento do cargo de gestor.

Redes municipais no Nordeste.
\end{abstract}

ABSTRACT: The Brazilian Northeast adopted, as did most regions, the democratic management, provided for in the Law on Directives and

* É formada em pedagogia e Mestre em Educação pela Universidade Federal de Alagoas. Atualmente é doutoranda do PPGE-UFAL, e membro do Grupo de Pesquisa sobre Gestão e Avaliação Educacional \{GAE). E-mail: <isabelamacena@yahoo.com.br>.

** É doutora em Educação Escolar pela Universidade Estadual Júlio de Mesquita Filho e Pós-doutora em Educação Escolar no Instituto de Educação da Universidade de Lisboa. Atualmente é professora associada da Universidade Federal de Alagoas e líder do Grupo de Pesquisa sobre Gestão e Avaliação Educacional \{GAE). E-mail:<wiledna@bol.com.br>. 
Basis of National Education (LDBEN) no 9394/96 as guiding principle of the form of provision for the position of school manager. This article aims to bring up how the school managers of the municipalities of five Northeastern Brazilian states: Alagoas, Ceará, Paraíba, Pernambuco and Rio Grande do Norte were or are being selected. With resources coming from Edital Universal- CNPq (Brazilian National Council for Scientific and Technological Development) it was possible to carry out the study, using a quanti-qualitative methodology.

Keywords: Democratic management. Provision of manager's office. Municipal networks in the Northeast.

RESUMEN: El nordeste brasileño adoptó, como la mayoría de las regiones, la gestión democrática, prevista en la Ley de Directrices y Bases de la Educación Nacional (LDBEN) nº 9394/96 como principio orientador de la forma de provisión al cargo de gestor escolar. Este artículo plantea como se procesó o se está procesando la elección del gestor escolar de los municipios de cinco estados del nordeste brasileño: Alagoas, Ceará, Paraíba, Pernambuco y Rio Grande do Norte. Este estudio, que utiliza una metodología cuantitativa y cualitativa, se realizó con fondos provenientes del Edital Universal-CNPq.

Palabras clave: Gestión democrática. Provisión del cargo de gestor. Redes municipales en el nordeste.

\section{Introdução}

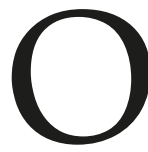

Nordeste é reconhecidamente um território de contrastes de origens históricas. Primeira região colonizada pelos diferentes povos europeus, destacando-se os portugueses; conheceu o apogeu econômico e amarga, ainda hoje, uma decadência secular. Não à toa, é o principal destinatário dos programas e projetos do Ministério da Educação (MEC) que visam à melhoria do perfil educacional das instituições públicas. Em tal direção, adotou como a maioria das regiões brasileiras a gestão democrática, prevista na Lei de Diretrizes e Bases da Educação Nacional (LDBEN) nº 9394/96 como princípio orientador da forma de provimento ao cargo de gestor escolar.

As pesquisas (Dourado e Costa, 1998, Lück, 2011; Paro, 2001, Vieira, 2001; etc.) têm demonstrado que o modelo central de provisão do cargo de diretor escolar sofreu profundas transformações nas redes públicas estaduais de ensino a partir da LDBEN; entretanto, poucos são os estudos que se preocupam com a realidade da educação municipal, de 
modo que não se tem uma noção clara do que se processou ou está se processando, particularmente no campo da gestão escolar dos municípios. Por isto, esta pesquisa apresenta uma análise inovadora sobre a realidade da gestão escolar municipal no Nordeste Brasileiro. A questão central que norteou a pesquisa foi a intenção de desvelar quais mudanças se processaram no modo de ocupação do cargo pelo gestor escolar nas secretarias de educação municipais, desde a implantação (no discurso oficial e na legislação) da gestão democrática pelo Governo Federal em 1996.

Como recorte temporal, tem como marco cronológico inicial a implantação da reforma da educação nos quadros da reforma do Estado, pois em tal período - que se inicia com os dois primeiros governos do presidente Fernando Henrique Cardoso (1995 a 2002) - se processou com mais veemência as mudanças (KRAWCZYKe VIEIRA, 2008).

Quanto à base teórico-metodológica, adotou-se uma abordagem quanti-qualitativa, visto que este estudo visou compreender os critérios de ocupação do cargo de diretor escolar, mapeando os modelos determinantes e analisando suas diferenciações locais assim como os pontos convergentes. Teoricamente, o estudo está referenciado em Dourado (1998; 2000; 2003) Paro (1986 e 2001), Vieira (2001) e Lück (2002, 2007, 2010 e 2011), que têm se dedicado à construção conceitual da gestão democrática no campo da educação escolarizada no Brasil.

Considerando esse reordenamento da administração nas unidades escolares públicas, este artigo visa apresentar um inventário das formas e configurações de provimento ao cargo de gestor escolar das redes públicas municipais de ensino nos estados de Alagoas, Ceará, Paraíba, Pernambuco e Rio Grande do Norte. Esse mapeamento meticuloso sobre a forma de provimento do cargo de gestor nas redes municipais dos cinco estados nordestinos traz, inegavelmente, contribuições para a produção de conhecimento sobre a gestão democrática na educação básica.

\section{A gestão democrática no Brasil: caminhos trilhados}

Relativamente jovem, porque tem apenas dezesseis anos de implantada, a gestão democrática da educação parece ser consenso entre os principais teóricos dos processos educacionais no Brasil contemporâneo. Porém, não há uma uniformidade na escolha dos dirigentes das escolas públicas nas redes estaduais e municipais.

O provimento do cargo tem-se dado basicamente por meio da indicação política, do concurso público, da eleição direta pela comunidade escolar (ou por lista plurinominal) e das formas mistas de escolha (provas e títulos, e eleição), constituindo-se estas últimas como oposição às formas autoritárias e verticalizadas, que marcaram e, por vezes ainda marcam, muitas redes de ensino. São, inegavelmente, tentativas concretas na busca de uma democratização da gestão escolar. (DOURADO e COSTA, 1998) 
Embora os estudos de Calaça (1993); Canesin (1993); Castro \& Werle (1991); Couto (1988); Paro (1996); Dourado (1990); Dourado e Costa (1998); Heeman (1986); Leal \& Silva (1987); Mendonça (1987); Paixão (1994); Werle (1991); entre outros, apontem a eleição do gestor escolar como uma das formas que mais se coaduna aos princípios da gestão democrática da educação, ainda é insuficiente o número de estudos sobre a existência da eleição como forma de provimento do cargo de gestor escolar nas redes municipais de educação. Há um predomínio de estudos sobre esta temática na esfera estadual e, quando municipal, as pesquisas (Dourado e Costa, 1998; Lück, 2011; Paro, 1996) centram-se nas redes municipais das capitais dos estados brasileiros.

Desde os anos de 1990 do século XX, os teóricos já indicavam a importância de estudos deste tipo para as discussões sobre a temática, pois, segundo Paro (1996, p. 9):

(...) a adoção das eleições como modalidade de escolha de dirigentes escolares continuou se expandindo nos vários sistemas de ensino, em especial nas redes de escolas municipais, justificando um estudo mais aprofundado.

Entretanto, parece haver certo "amornamento" da questão, como se a gestão democrática estivesse plenamente consolidada. Pode-se afirmar, a partir de um olhar mais atento sobre as redes municipais de ensino, que a gestão democrática enfrenta sérios problemas. Basta levar em conta a perspectiva da política local e o "mando" dos "vereadores" e dos "cabos eleitorais" nesse processo.

Ao longo da história recente do Brasil, há muitos mais exemplos de práticas esporádicas e pontuais de participação na gestão das escolas públicas do que propriamente dita uma gestão democrática tal qual o descrito na legislação educacional. Em outras palavras, a educação brasileira tem se caracterizado pelo aumento dos processos de democratização da gestão, o que merece grande destaque, mas se mantém ainda distante de um número elevado de sistemas e unidade escolares democráticos. A democracia não é um valor universal, um conceito neutro; ao contrário, a palavra é polissêmica e, justamente por apresentar várias acepções, seu uso, associado à ideia de participação, ganhou centralidade no cenário político desde o final do século $X X$, tanto na voz dos que se autodenominam representantes da esquerda ou da direita, dominantes ou dominados. Segundo Silva (2003 p. 12), "a facilidade com que o discurso democrático molda-se ao contexto das relações sociais e é encampado por distintas correntes políticas tem gerado ambiguidades que dificultam a tarefa de identificar as diferenças entre suas variantes". Desta forma, adota-se na presente pesquisa a definição de Bobbio (2000, p. 387), por enfatizar contrariedade a toda forma de autoritarismo:

[...] A definição de democracia como poder em público não exclui naturalmente que ela possa e deva ser caracterizada também de outras maneiras. Mas essa definição capta muito bem um aspecto pelo qual a democracia representa uma antítese de todas as formas autocráticas de poder. 
Nos dias atuais, é mais apropriado falar em níveis de democracia, logo, em níveis de gestão democrática da escola pública. Como nos mostra Machado (2008 apud McCOWAN, 2008 p. 57), especificamente sobre a realidade brasileira:

Em nosso país predomina uma democracia de baixíssima intensidade, com longos períodos de ditadura militar e regimes de exceção, sobre uma base colonial de quase quatro séculos de escravidão, na qual está enraizada uma cultura racista, excludente e autoritária que permeia toda a sociedade. Neste sentido, a empreitada utópica se faz mais difícil, contudo, não menos como meio de manter esta orientação [...] Nós não queremos desenvolver um plano democrático de forma autoritária - infelizmente, algumas administrações democráticas fazem exatamente isso: "vocês vão participar!" E as pessoas podem participar durante esta administração, mas quando muda o prefeito tudo vai por água a baixo. Então, temos que criar uma cultura da cidadania, na qual as pessoas possam desobedecer e confrontar mesmo que seja o nosso governo.

A cultura da obediência é ensinada nas escolas. Como ser um gestor, um profissional da educação democrático se ao longo de vários anos o que se aprendeu é a não contestação, a passividade e a submissão?

\section{Metodologia}

A base metodológica deste estudo buscou intercalar duas correntes teórico-metodológicas diferentes, mas não excludentes: qualitativa e quantitativa. As técnicas utilizadas foram quanti-qualitativas, considerando o objetivo geral da pesquisa que foi investigar as formas de provimento do cargo de gestor escolar nas redes públicas municipais de ensino nos estados de Alagoas, Ceará, Paraíba, Pernambuco e Rio Grande do Norte, apontando os aspectos centrais e secundários nesse processo de implantação.

Envolvendo cinco estados com realidades sociais não totalmente díspares, a base empírica do estudo foi as secretarias municipais de educação. Assim, foram realizadas consultas on line (correspondência eletrônica) e por Correios às secretarias de educação de todos os 861 (oitocentos e sessenta e um) municípios dos cinco estados e à União dos Dirigentes Municipais de Educação (Undime/AL, CE, PB, PE e RN) sobre a forma de preenchimento dos cargos de gestor escolar. As seções estaduais da Associação Nacional de Política e Administração da Educação (Anpae) dos cinco estados também foram consultadas sobre a existência de dados locais sobre a temática em questão.

Em princípio o contato telefônico não estava previsto, mas, diante do baixo índice de retorno dos e-mails, optou-se por esta forma de coleta de dados, a qual se mostrou bem efetiva. Foram três perguntas aos secretários ou técnicos das secretarias sobre a gestão escolar nos municípios dos cinco estados nordestinos, sendo elas: 1 ) O município tem Conselho Municipal de Educação, em caso afirmativo, desde quando? 2) O município 
tem Plano Municipal de Educação, em caso afirmativo, quando foi elaborado? 3) Quais as formas de provimento do cargo de gestor escolar? Neste artigo priorizamos a análise da pergunta de número 3 , que diz respeito às formas de provimento ao cargo de gestor escolar dos 861 (oitocentos e sessenta e um) municípios dos cinco estados.

\section{As formas de provimento do cargo de gestor escolar}

A partir da metodologia apresentada foi possível chegar aos resultados da pesquisa que são demonstrados com mais propriedade no mapa a seguir:

\section{Imagem 1: Formas de provimento ao cargo de gestor escolar no Nordeste}

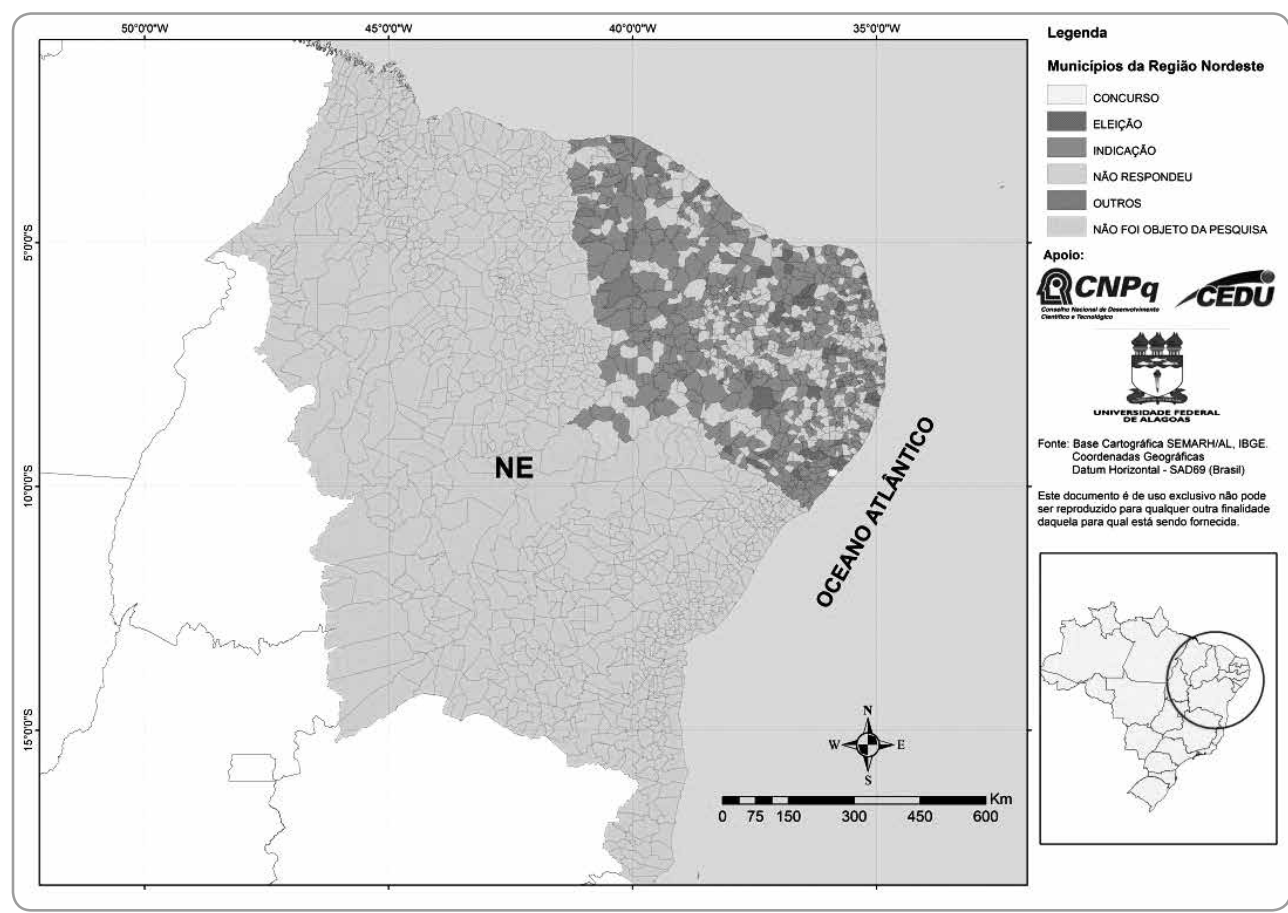

Fonte: Dados da Pesquisa

Como se observa acima, nos cinco estados da região Nordeste há uma forte predominância da indicação político partidária e um número mínimo de escolha do gestor escolar por eleição. A expressão indicação político partidária é usada pelas autoras, porque os gestores municipais são agentes políticos partidários, portanto, suas indicações são também políticas. Dos 861 (oitocentos e sessenta e um) municípios pesquisados, 485 (quatrocentos e oitenta e cinco) ainda escolhem o gestor por meio de indicação político 
partidária. Enquanto apenas 42 (quarenta e dois) escolhem por eleição direta e 24 (vinte e quatro) por outras formas como seleção pública, concurso ou lista tríplice. 310 (trezentos e dez ) secretários municipais se recusaram a responder, mesmo quando indagados, o que parece indicar que nesses locais, também, não há eleições ou outra forma de escolha de gestor, pois, se houvesse, qual sereia o motivo do silêncio ou da recusa explícita em responder à indagação?

A prevalência da indicação política para o cargo de gestor escolar, como enfatiza Paro (2003), traz consigo as marcas do clientelismo político, sendo por isso uma das mais criticadas, mesmo que esteja, ainda, muito presente nos sistemas de ensino de algumas regiões brasileiras, em especial nas do Norte e Nordeste. Tais dados demonstram em números essa realidade, por isso pode ser considerado um estudo inédito sobre a gestão escolar no Nordeste Brasileiro.

Os dados coletados também evidenciam que os determinantes que influenciam a estrutura de ocupação do cargo de gestor escolar são condicionados ao mandato do gestor municipal. Em alguns casos, houve por parte dos secretários certo constrangimento em afirmar que o município ainda escolhe o gestor por meio de indicação, por isso utilizaram respostas que tentam contornar a realidade como "não é totalmente indicação, nós avaliamos o tempo de serviço, a formação e a competência enquanto professor".

A afirmação de Faoro (1958) de que o poder esteve sempre concentrado nas mãos de poucos desde a formação social e política brasileira parece ainda atual ao analisarmos esses dados sobre a educação no Nordeste do Brasil. Muitos secretários explicitam a existência de práticas típicas do "velho" coronelismo brasileiro, travestido com novas roupagens, ao se considerar a dinâmica da história, podendo ser chamado de um neocoronelismo. Sobre a origem e conceito de coronelismo, Leal (1975: 50) afirma:

É uma fonte específica de poder, que floresceu durante a 1 ${ }^{a}$ república, e cujas raízes remontavam ao império; já então os municípios eram feudos políticos, que se transmitiam por herança, não configurada legalmente, mas que existiam de maneira informal.

Os resultados da pesquisa permitem que se percebam, também, os limites da ação dos secretários municipais e dos gestores escolares frente à perseguição política, à obediência pelo medo de perder o cargo e os entraves de uma gestão educacional presa às amarras de relações políticas autoritárias e negadoras do exercício da sua cidadania , expressão máxima da força do clientelismo político como um instrumento de cooptação de votos, ou seja, do sistema de trocas também conhecido como favores políticos. Segundo Brachet-Márquez (1992, p. 93) “Clientelismo se refere à estruturação do poder político através de redes de relações informais que ligam indivíduos com poder desigual em relações de troca". No Brasil, e principalmente na Região Nordeste, o clientelismo ainda ocupa uma posição relevante no cenário da organização política, o que se reflete também nas instituições escolares, como evidenciado nos dados do quadro a seguir: 


\section{Quadro 1: Provimento do Cargo de Gestor Escolar em Cinco estados do Nordeste}

\begin{tabular}{l|c|c|c|c|c}
\hline & AL & CE & PB & PE & RN \\
\hline Eleição & 11 & 1 & 4 & 8 & 18 \\
\hline Indicação & 70 & 113 & 97 & 105 & 100 \\
\hline Outros modelos & 2 & 20 & --- & -- & 2 \\
\hline Não respondeu & 19 & 50 & 122 & 72 & 47 \\
\hline Total & 102 & 184 & 223 & 185 & 167 \\
\hline
\end{tabular}

Fonte: Dados da Pesquisa

Os estados de Ceará e Pernambuco têm uma equiparação, como evidencia o número de municípios: um 184 (cento e oitenta e quatro) e outro 185 (cento e oitenta e cinco), respectivamente. O que possibilita fazer comparações, sendo que nos dois estados a forma predominante de escolha do gestor escolar é a indicação político-partidária. 113 (cento e treze) municípios no estado do Ceará escolhem o gestor por indicação; enquanto 20 (vinte) escolhem por outras formas, dentre elas a mais citada é a seleção pública, presente em 13 (treze) municípios, correspondendo a 7,1\% do total.

Os secretários e técnicos que deram as respostas enfatizaram que esta forma de seleção é uma experiência ainda recente e que se espera obter mais êxito com ela. A seleção pública, segundo Schneckenenberg (2009), é uma das formas em que se tenta encontrar gestores com conhecimento e formação sólidos, a fim de que eles se apropriem das práticas educacionais, com autonomia, exercendo um papel de articulador das atividades. Nos municípios do estado de Pernambuco, após a indicação político-partidária, a segunda forma mais utilizada de escolha do gestor escolar é a eleição direta, mas, apenas 08 (oito) municípios apresentam essa forma de provimento.

Os estados de Alagoas e Rio Grande do Norte são os que possuem o menor número de municípios, 102 (cento e dois) e 167 (cento e sessenta e sete), respectivamente. Todavia, não mostraram grandes avanços com relação à forma de provimento do cargo de gestor escolar. No Rio Grande do Norte, 100 (cem) municípios têm como forma de provimento do cargo a indicação política, 18 (dezoito) a eleição, 02 (dois) outras formas (aclamação por assembleia e seleção pública) e 47 (quarenta e sete) não responderam. Nas respostas dos secretários do Rio Grande do Norte, houve hibridismos, com afirmações de que o provimento do cargo de gestor escolar pode acontecer tanto por indicação e/ou eleição como mostram alguns: "Nas escolas abaixo de 100 alunos o gestor é escolhido por indicação, acima desse total por eleição" ou "Ensino fundamental, eleição, e na educação infantil, indicação".

Em Alagoas, apenas 11 (onze) dos 102 (cento e dois) municípios entrevistados apresentam eleição de diretores nas escolas públicas municipais. Em 70 (setenta) municípios, o cargo de diretor é provido por nomeação/indicação política. Interpretando os dados, 
percebe-se que os municípios alagoanos que usam a indicação política como forma de provimento ainda não avançaram na busca por uma verdadeira gestão democrática nas escolas. No entanto, merece destaque a afirmação de Paro (2003) de que a eleição de diretores não resolverá todos os problemas escolares, pois não se constitui como único meio pelo qual se efetivará a gestão democrática, mas é, sem dúvida, uma das importantes ações para o alcance da gestão democrática na escola pública brasileira. Constitui-se, portanto, como um passo inicial na longa caminhada em busca da tão propagada gestão democrática.

O estado da Paraíba, com 223 (duzentos e vinte e três) municípios, o maior número em relação aos estados pesquisados, apresentou apenas 04 (quatro) municípios com eleição; todavia foi o estado em que os secretários mais se recusaram a responder a pergunta sobre a forma de provimento do cargo de gestor escolar. As justificativas foram desde "Não temos essa informação no momento" ou "Preferimos não responder a esta pergunta". Mas como instituir um espaço democrático nas escolas, se os próprios secretários têm receio em responder uma pergunta sobre a forma de provimento do cargo do gestor escolar? A concretização de um modelo de gestão democrática requer romper com o clientelismo político e envolver a participação de todos os sujeitos nas decisões sobre os rumos da educação.

Analisa-se, assim, que nenhum dos estados mostrou avanços significativos a partir do preconizado, desde 1988, pela Constituição Federal e, mais tarde, em 1996, pela a LDBEN no 9394 . Os resultados são inquietantes, confirmando que a educação necessita de "uma prática que mude a realidade. Mas a consciência se põe, como condição imprescindível dessa práxis" (PARO, 2001, p. 30). É preciso que a participação, elemento fundamental da democracia, seja ensinada na escola desde as ações mais corriqueiras às mais sérias, tais como escolha do diretor escolar pelo voto direto; a construção coletiva do projeto político pedagógico (PPP); a constituição dos conselhos escolares autônomos e atuantes, dentre outros mecanismos. Para se alcançar um nível adequado de gestão democrática é indispensável que os sujeitos, antes de tudo, aprendam a participar, passo essencial, como afirma Garske e Torres (2000, p.67) "Não é possível pensar em democracia plena sem sujeitos democráticos para exercê-la".

Quanto à forma de provimento do cargo por eleição, defendida por muitos estudiosos da área, o estado que demonstrou um maior número de municípios com eleição foi o estado do Rio Grande do Norte, com 18 (dezoito), enquanto o estado do Ceará foi dos cinco Estados o que menos avançou nesse sentido, com apenas 1(um) município elegendo o diretor escolar. Por outro lado, o estado do Ceará foi o que mais apresentou outras formas de provimento, tendo 20 (vinte) que escolhem o gestor por meios como seleção pública e concurso.

Portanto, o modo das secretarias municipais de educação dos estados nordestinos se organizarem com relação ao provimento do cargo de gestor escolar evidencia a ênfase 
de um interesse político partidário em detrimento da verdadeira participação popular na gestão das escolas públicas. E isso interfere, inegavelmente, na autonomia dos gestores escolares, na participação da comunidade nas decisões escolares e na formação de cidadãos críticos, especialmente na Região Nordeste, que, mesmo tendo uma evolução nos últimos anos, ainda concentra mais da metade dos analfabetos do País, o que, segundo dados do Instituto Brasileiro de Geografia e Estatística (IBGE, 2011), corresponde a 52,7\% do total de analfabetos.

\section{Considerações finais}

Buscou-se, neste artigo, apresentar os resultados de uma pesquisa financiada pelo Edital Universal - CNPq cujo objetivo central foi analisar as formas e configurações de provimento ao cargo de gestor escolar das redes públicas municipais de ensino em cinco estados da Região Nordeste do Brasil.

Mesmo com as transformações sofridas no modelo central de provisão do cargo de diretor escolar nas redes públicas de ensino a partir da Constituição Federal de 1988 e da Lei de Diretrizes e Bases da Educação Nacional no 9394/96 e com inúmeras pesquisas (HEEMANN \& PUCCI,1986; DOURADO,1990; CASTRO,1991; CALAÇA (1993); PARO,1996; OLIVEIRA, 1996; WERLE, 2001) apontando a eleição do gestor escolar como uma das formas que mais se coadunam aos princípios da gestão democrática da educação, nas redes públicas municipais dos estados de Alagoas, Ceará, Paraíba, Pernambuco e Rio Grande do Norte houve poucos avanços nestes 25 anos de promulgação da Carta Magna brasileira e da lei maior da educação nacional.

Os resultados finais mostram que na maioria dos municípios dos cinco estados pesquisados na Região Nordeste, a indicação política ainda é a única forma de provimento do cargo de gestor escolar, o que tem contribuído para perpetuar o fisiologismo, o mandonismo e o nepotismo, marcas seculares arraigadas na sociedade nordestina. Os dados mostram que poucas mudanças se processaram no modo de ocupação do cargo pelo gestor escolar nas secretarias de educação municipais desses cinco estados, desde a implantação da gestão democrática pelo Governo Federal, em 1996.

Contudo, o pioneirismo dos dados aqui apresentados sobre os processos de gestão educacional em estados da Região Nordeste podem servir de fonte para novas pesquisas, com análises mais profundas, sobre a realidade dessa importante região que há anos amarga os piores índices educacionais do País.

Recebido em: 03/05/2018, Reapresentado em: 07/10/2018 e Aprovado em: 12/10/2018 


\section{Referências}

AGUIAR, Maria Ângela e ALLOUFA, Jomária Mata de Lima. Formação de administradores da Educação: relatório final de pesquisa. Série Estudos e Pesquisas, n. 2. Brasília: ANPAE, 1998.

ALONSO, Mirtes. O papel do diretor na administração escolar. Rio de Janeiro: Bertrand, 1988. AMARAL SOBRINHO, José; XAVIER, Antonio Carlos da R.; MARRA, Fátima. Gestão da escola fundamental: situação atual e tendências. In.: XAVIER, Antonio Carlos da R; AMARAL SOBRINHO, José; MARRA, Fátima. Gestão escolar: desafios e tendências. Brasília: IPEA, 1994.

ARAÚJO, Sergio Onofre de. Gestão Democrática? Os desafios de uma gestão participativa na educação pública em uma sociedade clientelista e oligárquica. Maceió: EDUFAL, 2007.

BRACHET-MÁRQUEZ, Viviane. Explaining sociopolitical change in Latin America: the case of Mexico. Latin American Research Review, EUA, The Latin American Studies Association n. 3, v. 27, p. 91-122, 1992.

BRASIL. Lei de Diretrizes e Bases da Educação Nacional. Lei 9.394/96. Brasília: 1996.

BOBBIO, Norberto. Democracia. Liberalismo e Democracia. 6a ed. São Paulo: Brasiliense, 2005.

CALAÇA, Celina Ferreira. Eleição de diretor de escola e gestão democrática: um estudo de caso. 1993. 232 f. Dissertação (Mestrado em Educação) - Pontifícia Universidade Católica de São Paulo, São Paulo, 1993.

CASTRO, Marta Luz Sisson de et al. Eleição de diretores: a experiência do Estado do Rio Grande do Sul. Revista Brasileira de Administração da Educação, ANPAE, Porto Alegre, v. 7, n. 1 - 2, p. 80-102, jan./dez. 1991.

CANESIN, Maria Tereza. Um protagonista em busca de interlocução: um resgate da história do movimento de professores da rede pública de $1^{0}$ e $2^{0}$ graus em Goiás, na conjuntura 1979/1989. São Paulo: Tese de Doutorado, PUC-SP, 1993.

COUTO, Jurema Barbieri. Gestão democrática na escola pública: o caso do Distrito Federal (1985-1988). Brasília: Dissertação de Mestrado, UnB, 1988.

DOURADO, Luiz Fernandes. Democratização da escola: eleições de diretores, um caminho? Dissertação Mestrado, Faculdade de Educação da Universidade Federal de Goiás-UFG, Goiânia, 1990.

DOURADO, Luiz Fernandes; COSTA, Messias. Escolha de dirigentes escolares no Brasil. Relatório final de pesquisa. Brasília: ANPAE, 1998.

DOURADO, Luiz Fernandez. A escolha dos dirigentes escolares: políticas e gestão da educação no Brasil. In FERREIRA, Naura Syria Carapeto (org.). Gestão Democrática da Educação: atuais tendências, novos desafios. São Paulo: Cortez, 2000.

DOURADO, Luiz Fernandes. (org.). Gestão escolar democrática: a perspectiva dos dirigentes escolares da rede municipal de ensino de Goiânia-GO. Goiânia: Alternativa, 2003.

FREIRE, Paulo. Pedagogia da autonomia. São Paulo: Cortez, 1997.

FAORO, Raymundo. Os Donos do Poder: Formação do Patronato Político Brasileiro. Rio de Janeiro/ Porto Alegre/São Paulo, Editora Globo, 1958. 
GADOTTI, M. e ROMÃO, J. E. Autonomia da escola: princípios e propostas. São Paulo: Cortez Editora: IPF, 2004.

GARSKE, L. M.; TORRES, A. Diretores de escola: o desacerto com a democracia. Em Aberto, INEP, Brasília, v. 17, n. 72, p. 60-70, fev./jun. 2000.

GISESKI, Ângela Antunes et.al. Gestão democrática do ensino público: escolha de diretores. Brasília: Instituto Paulo Freire/ Conselho Nacional de Secretários de Educação, 1996.

HEEMANN, Eliana Barbosa; PUCCI, Francisco César de Luca. A eleição dos diretores das escolas estaduais do Paraná e seus efeitos na vida da escola. Curitiba, UFPA, 1986.

HYPÓLITO, Álvaro Moreira; LEITE, Maria Cecília; DALL'IGNA, Maria Antonieta; MARCOLLA, Valdinei. Gestão Educacional e Democracia Participativa. Porto Alegre: Editora da UFRGS, 2008.

IBGE, Instituto Brasileiro de Geografia e Estatística. Censo 2010. Disponível em http://www.ibge. gov.br. Acesso em 11/12/2010.

IBGE, Instituto Brasileiro de Geografia e Estatística. Pesquisa Nacional por Amostra de Domicílios (Pnad) 2011. Disponível: em< http://www.ibge.gov.br/home/estatistica/populacao/ trabalhoerendimento/pnad2011/>. Acesso 17 jul 2014.

KRAWCZYK, N. R; VIEIRA, V. L. A reforma educacional da América Latina nos anos 1990: uma perspectiva histórico-sociológica. São Paulo: Xamã, 2008.

LEAL, Victor Nunes. Coronelismo, Enxada e Voto: O Município e o Regime Representativo no Brasil. São Paulo: Alfa-ômega, 1975.

LEAL, Elisabeth Juchem Machado \& SILVA, Virgínia Maria de Figueiredo e. Diretores eleitos: dilemas emergentes da greve do magistério de 1987 em Santa Catarina. Revista Brasileira de Administração da Educação. Porto Alegre: 5(1):62-77, jan.jjun. 1987.

LÜCK, Heloisa. Mapeamento de práticas de seleção e capacitação de diretores escolares. Relatório Final da pesquisa. Curitiba: Fundação Vitor Civita/CED HAP, 2011.

LÜCK, Heloísa. Dimensões da gestão escolar e suas competências. Curitiba: Positivo, 2009.

LÜCK, Heloísa. Concepções e processos democráticos de gestão educacional. Petrópolis: Vozes, 2010.

LÜCK, Heloísa. Gestão educacional: uma questão de paradigmas. Petrópolis: Vozes, 2010.

MARÉS, Carlos. Eleição de diretores e democracia na escola. Revista da ANDE, São Paulo: ANDE, v.3, 1983, p.49-50.

MARTINS, Ângela Maria (org.). Estado da Arte: gestão autonomia escolar e órgãos colegiados (20002008). Brasília: Liber Livro, 2011.

MCCOWAN, Tristan. Educando cidadãos para a democracia participativa: um estudo de caso das políticas educacionais de um governo municipal de Pelotas. In: HYPÓLITO, Álvaro Moreira; LEITE, Maria Cecília; DALL'IGNA, Maria Antonieta; MARCOLLA, Valdinei. Gestão Educacional e Democracia Participativa. Porto Alegre: Editora da UFRGS, 2008.

MENDES, Valdelaine. A participação da comunidade escolar na definição de uma política educacional. In: HYPÓLITO, Álvaro Moreira; LEITE, Maria Cecília; DALL'IGNA, Maria Antonieta; MARCOLLA, Valdinei. Gestão Educacional e Democracia Participativa. Porto Alegre: Editora da UFRGS, 2008.

MENDONÇA, Erasto. A gestão democrática nos sistemas de ensino brasileiros: a intenção e o gesto. Dispon ível em http://sala.clacso.org.ar/gsdl/cgi-bin/anped. Acesso em 23/04/2011. 
MENDONÇA, Erasto Fortes. A eleição de diretores do ensino público do DF: avanço ou manipulação? Revista Brasileira de Administração da Educação. ANPAE, Porto Alegre: 5(2):49-62, jul./dez. 1987.

OLIVEIRA, Ana Angélica Rodrigues de. Eleição para diretores e a gestão democrática da escola pública. São Paulo: Alfa-Omega, 1996.

PARO, Vitor Henrique. Administração escolar: introdução crítica. São Paulo: Cortez, 1986.

PARO, Vitor Henrique. Eleição de diretores: a escola pública experimenta a democracia. Campinas: Papirus, 1996.

PARO, Vitor Henrique. Gestão Democrática da Escola Pública. São Paulo: Ática, 2003.

PAIXÃO, Regina da. O colegiado escolar como instrumento de gestão participativa: a vivência de Mato Grosso do Sul. In: XAVIER, Antonio Carlos da R.; SOBRINHO, José Amaral; e MARRA, Fátima (orgs.). Gestão escolar: desafios e tendências. Brasília. IPEA, 1994. P. 107-122.

SAES, Décio Azevedo Marques de e ALVES, Maria Leila. Conflitos ideológicos em torno da eleição de diretores de escolas públicas. Texto apresentado na 27a. Reunião Anual da ANPED, Grupo de Trabalho 05. Caxambu, MG, 2004 IN: http://www.anped.org.br/reunioes/27/gt05/t053.pdf. Acesso em 17/05/2010.

SILVA, I.G. Democracia e participação na reforma do Estado. São Paulo: Cortez, 2003.

SCHNECKENENBERG, Marisa. Democratização da gestão e atuação do diretor de escola municipal. Revista Brasileira de Política e Administração da Educação. Porto Alegre, ANPAE, v. 25, n. 1, p. 115137. Jan./abr.2009.

URANI, André. Um diagnóstico socioeconômico do Estado de Alagoas a partir de uma leitura dos dados da Pesquisa Nacional por Amostra de Domicílios do IBGE (1992-2004). Instituto de Estudos do Trabalho e Sociedade. Maceió, 2005.

VIEIRA, Sofia Lerche. Eleição de diretores: o que mudou na escola? Brasília: Plano, 2001.

WERLE, Flávia Obino Corrêa. Novos tempos, novas designações e novas demandas. Revista Brasileira de Política e Administração da Educação, Piracicaba, ANPAE, v. 17, n. 2, p. 147-160, jul./dez. 2001.

XAVIER, Antônio Carlos da Ressurreição; AMARAL SOBRINHO, José; MARRA, Fátima (Org.). Gestão da escola fundamental: situação atual e tendências. In: XAVIER, Antônio Carlos da Ressurreição; AMARAL SOBRINHO, José; MARRA, Fátima (Org.). Gestão escolar: desafios e tendências. Brasília, DF: Instituto de Pesquisa Econômica Aplicada, 1994. p. 51-86. 